\title{
PSYCHOLOGICAL CHARACTERISTICS OF ELDERLY PATIENTS WITH ORAL DISEASES
}

\author{
Rozeta DRAGHICI ${ }^{1}$, Andrei KOZMA ${ }^{2,3 凶}$, Anna M. HERGHELEGIU1 ${ }^{1}$, Alexandra RUSU ${ }^{1}$, \\ Raluca M. NACU ${ }^{1}$, Gabriel-Ioan PRADA ${ }^{1}$
}

${ }^{1}$ „Ana Aslan“ National Institute of Gerontology and Geriatrics, Bucharest, Romania

2 „Alessandrescu-Rusescu“ National Institute for Mother and Child Health, Bucharest, Romania

${ }^{3}$ Academy of Romanian Scientists

Received 16 Jan 2019, Accepted 24 Febr 2019

https://doi.org/10.31688/ABMU.2019.54.1.21

\begin{abstract}
The proportion of older people continues to grow worldwide. This, along with an increase in the prevalence of oral diseases, will significantly challenge health and social policy planners. Oral health is often neglected in the elderly and oral diseases associated with aging are complex, adversely affecting the quality of life. Identifying the psychopathology or the type of deviation from normality in the elderly, involves the assessment of psychological health and the operation with the psychological health major symptomatology. One of the dentist's difficulties may be the recognition of a particular disorder in the case of an individual who is accusing a suffering state. The communication between the doctor and the elderly patient, which is the key in geriatric practice, is not optional, because it helps to achieve an efficient medical act in an appropriate, relevant and satisfactory manner for the care of the elderly patient. Discussion with the patient should be appropriate to the level of understanding of the individual elderly person. The patient's cooperation is essential for any type of dental treatment. The biopsychosocial concept is fundamental to find an optimal treatment for oral diseases. The oral health influences the mental health of patients, changing their
\end{abstract}

\section{RÉSUMÉ}

Caractéristiques psychologiques des maladies orales chez les personnes âgées

La proportion de personnes âgées continue de croître dans le monde entier. Ceci, associé à une augmentation de la prévalence des maladies bucco-dentaires, posera un défi considérable aux planificateurs de la santé et des politiques sociales. La santé bucco-dentaire est souvent négligée chez les personnes âgées et les maladies bucco-dentaires associées au vieillissement sont complexes et nuisent à la qualité de la vie. Identifier la psychopathologie ou le type d'écart par rapport à la normalité chez les personnes âgées, implique l'évaluation de la santé psychologique et le fonctionnement avec la symptomatologie majeure de santé psychologique. Une des difficultés du dentiste peut être la reconnaissance d'un trouble particulier dans le cas d'un individu accusant un état de souffrance. La communication entre le médecin et le patient âgé, clé de la pratique gériatrique, n'est pas facultative, car elle permet de réaliser un acte médical efficace de manière appropriée, pertinente et satisfaisante pour le traitement du patient âgé. La discussion avec le patient doit être adaptée au niveau de compréhension de la personne âgée. La coopération 
self-esteem, mood and satisfaction, even influencing their social life and quality of life. This is an important factor that has a direct influence on the general health and quality of life of older people, fundamental factors for „healthy aging".

Keywords: oral diseases, psychological characteristics, anxiety, communication, elderly patient.

\section{INTRODUCTION}

According to the World Health Organization (WHO), the global population is increasing at the annual rate of $1.7 \%$, while the population of those over 65 years old is increasing at a rate of $2.5 \%$. The proportion of older people continues to grow worldwide, especially in the developing countries. This, along with an increase in the prevalence of oral diseases, will significantly challenge health and social policy planners. Oral health is often neglected in the elderly and oral diseases associated with aging are complex, adversely affecting the quality of life 1 .

The aging phenomenon is a global reality, affecting more and more countries over the past decades, and Romania is no exception.

A consequence of demographic changes is that with the increase of the number of elderly patients due to changes in the aging process, pathology is increased through systemic ailments, but also morbidity through oral diseases. The existential problems encountered in the elderly are influenced by a number of biological, psychological or social parameters that may cause difficulties in carrying out normal activities and may increase the pathology of this population. Maintaining oral health, a part of the general health that is influenced by or it influences it, has a particular impact on the mental state and social integration of the elderly.

The interdisciplinary team. The physician should take a complex and complete look at the patient, correlate the dental diagnosis with the general pathology of the patient, to acquire a complete approach to clinical cases. It should possess knowledge from all medical fields and guide the process of developing the therapeutic solution, which the general health of the patient permits, to take into account the population category to which it is addressed ${ }^{2,3}$. du patient est essentielle pour tout type de traitement dentaire. Le concept biopsychosocial est fondamental pour trouver un traitement optimal pour les maladies bucco-dentaires. La santé bucco-dentaire influence la santé mentale des patients, en modifiant leur estime de soi, leur humeur et leur satisfaction, voire en influençant leur vie sociale et leur qualité de vie. C'est un facteur important qui a une influence directement sur la santé générale et la qualité de vie des personnes âgées, facteurs fondamentaux du „vieillissement en bonne santé“".

Mots-clés: maladies bucco-dentaires, caractéristiques psychologiques, anxiété, communication, patient âgé.

At this age, many patients already have diabetes, heart disease, have had infarcts or vascular accident, have Parkinson or even Alzheimer's disease. Generally, elderly patients tend to hide or even forget these diseases. Not knowing or ignoring overlapping affections can become a problem and complications become difficult to control in a dental office, especially when the patient does not honestly or fairly declare the problems. The predisposition to untreated complications, sometimes detrimental hygiene due to „negligence", alcohol consumption, depression, complements the chain of problems. It is noteworthy that depression in the elderly would be a concern considering the significant increase. One symptom of this mental illness is a lack of interest in performing daily activities, which influences the deterioration of oral hygiene.

In this context, addressing the oral diseases of the elderly requires a multidimensional approach to achieve good results.

For a general illness series, especially mental illnesses, in dental treatment it is necessary to consult with other specialists. In this context, there is of course the idea of working in a team, of interdisciplinary medical collaboration with the specialists who have a monitoring and treatment grant, only in this way one can avoid the possible accidents and complications during the dental therapeutic intervention.

One of the dentist's difficulties may be the recognition of a particular disorder in the case of an individual who is accusing „a suffering state“. Identifying the psychopathology or the type of deviation from normality in the elderly involves the assessment of psychological health and the operation with the psychological health major symptomatology.

The application of psychology to gerontological dentistry implies an interference of general psychology, medical, social and clinical geriatric psychology, especially in psychodiagnoses and geriatric 
psychological assessment. Recognizing and identifying characteristics, attributes, states, traits and personality structures that characterize the complexity of the human being assume understanding of human behavior.

Knowing some notions of the aging psychology it represents a vital tool for the following reasons:

- the necessity of an accessible approach of the elderly patient, by facilitating a dialogue based on a more complete understanding;

- the ability to support the development of an accurate diagnosis;

- the necessity of employing the family of the subject in therapeutic actions, being properly and scientifically informed about the psychological modifications of the elderly, which are not pathological nor intended, being objective and independent of the will of the subject;

The psychological knowledge allows a greater and more complete evaluation of the patient, of his sociological, biological and psychological dimensions, in his own dynamic assembly, like a total human, especially in the elderly ${ }^{4}$.

The communication between the doctor and the elderly patient, which is the key in the geriatric practice, is not optional, because it helps to achieve an efficient medical act in an appropriate, relevant and satisfactory manner for the care of the elderly patient. Discussion with the patient should be appropriate to the level of understanding of the individual elderly person.

The first contact with the patient is defining for establishing the relationship between physician and elderly patient; it should provide to physician the opportunity of collecting a wealth of informative material that allows him to know the patient, an optimal conduct in the relationship with the patient and useful information about the specific therapeutic attitude. This first meeting is also important for the patient, for his confidence that the doctor will be able to competently manage his or her oral health problems ${ }^{5}$. A well-guided history, with special attention to the patient's health problems and its peculiarities, an appropriate attitude to his psychological pattern, are some of the conditions for a quality treatment. Patient's health status correlated with his quality of life present a major personal role on the decision of the treatment plan. It is a tool for understanding and outlining the clinical practice and the success of the therapeutic act ${ }^{6}$. In fact, any patient, especially those with special needs, the elderly patient, anxious, with behavioral deviations, may become at any time the victim of incidents, accidents, complications of treatment if the physician ignores the individualized aspect of his behavior in relation to the patient.
Preventing any inconvenience during treatment becomes a must that can be achieved through clinical examination made with tact and patience through a set of simple and explicit questions capable of highlighting possible health problems of the elderly patient and allowing the correct diagnosis of the condition $^{7}$. In certain situations, the caregiver is the most appropriate person to provide this behavioral history.

\section{Psychological CONSIDERATIONS IN GeRIATRIC DENTAL PLANNING}

In the process of planning a dental treatment for a geriatric case, the following psychologically important factors should be considered:

a. Mental status: level of understanding and communication of the elderly patient.

b. Psychological needs: aesthetic and functional factors that would improve the individual's image of himself and ease his integration into society.

c. Obtaining the elderly patient's agreement: the patient can express his consent for the proposed treatment on his own, or it should be obtained from another person or institution.

In the psychopathological evaluation of the elderly, the following issues should be considered:

- the changes caused by aging on the central nervous system;

- the changes caused by the aging on other organs and systems;

- the particular psychological aspects of the elderly;

- the sociocultural attitude toward elderly ${ }^{4}$.

The attitudinal or subjective factors that are known to influence the older people's utilization of dental services directly or indirectly can be: personal beliefs; feeling no need, perceived need; perceived importance; fear and anxiety; resistance to change; perceived financial strain; satisfaction with dental visits ${ }^{8}$.

\section{Anxiety in gerontological dentistry}

A study of dentally anxious adults in the West Midlands ${ }^{9}$ found that $25 \%$ of respondents cancelled or deferred dental appointments as a direct result of their anxiety. Fewer elderly adults admit to being highly nervous of dentistry. Anxiety, stress and pain are a universal problem of all ages and dentistry has been always associated as inseparables.

All anxiety disorders share elements of fear and anxiety ${ }^{10}$, where the former is an emotional response to a real or perceived threat, while the latter concerns expectations of a future threat. As a result, anxiety in dentistry has two implications in routine clinical practice: (a) the high prevalence of anxiety disorders and depression in the general population, which may make patients anxious during dental care as a result 
of trait anxiety; (b) a high prevalence of specific dental anxiety and phobia ${ }^{11}$.

Generally, patients with different dental conditions are quite reluctant when following a specialist consultation or treatment procedures. Any dental care is traumatic, even for a clinically healthy patient, and even more so when talking about patients under particular conditions, the elderly. This anticipatory anxiety is manifested by a state of restlessness, extreme emotional tension that is accentuated when the patient is placed in the dental chair. The main factors of anxiety are dental pain, dental discomfort, dental cut, dental bleeding, fear of being injured, anesthetic injections, fear of the possibility of an allergy. The reduction of this state of anxiety is based on the reduction of pain through the analgetic effect and / or psychotherapeutic procedures such as musicotherapy, aromatherapy, cognitive-behavioral psychotherapy. Various methods of relaxation effect are useful in the dental practices.

In clinically healthy patients, but especially in those with a history of psychiatric problems, psychomotor agitation may occur with a high frequency and are caused by an exaggerated increase of emotions, frequent in both sexes. These patients can easily be traced in the anamnesis phase with logorrhea, psychomotor agitation, they can be recalcitrant, non-cooperative, with the tendency to indicate to the doctor a certain type of treatment and sometimes going as far as to refuse any treatment that is not approved by them ${ }^{12,13}$.

Hypertension with slight nausea and vomiting may occur in the patient with a hypertension history and can be determined by the state of fear of dental treatment ${ }^{14,15}$.

\section{Patient's cooperation is essential for any type of dental treatment.}

In people with disabilities, the opportunity for orthodontic treatment should be analyzed according to the characteristics of each case. Patient's cooperation is essential for this type of treatment. Patients with cognitive impairment have a reduced tolerance capacity to treatment sessions. Prior to orthodontic treatment, the patient's ability to understand and tolerate the discomfort caused by dental movements, to protect the orthodontic device during mastication, etc. should be observed. The choice of optimal orthodontic treatment is made after evaluating the psychological, functional, family and social requirements of the patient.

Alzheimer's patients have poor hygiene with increased prevalence of periodontal disease and tooth injuries. The inability to perform proper oral hygiene results, in particular, from impairment of cognition, apraxia and apathy in the intermediate stage of the disease. It is important for the patient to be assisted in performing oral care procedures, either from home cares or from specialized staff as the disease progresses. The goal of dental treatment in the Alzheimer's patients is to provide a realistic and meaningful solution to the patient's problems, which can positively influence the quality of life. Complex dental procedures including dental extractions and dental restorative procedures should be carefully planned in these patients as it could trigger intense anxiety in the Alzheimer's patients.

If the patient has a severe neurological deficit and is for the first time in front of a mobilizable prosthesis, he usually does not have the ability to adapt optimally to the prosthesis. Other devices, such as occlusal guides, are indicated if the patient can adapt to them and if there is no risk of aspiration and obstruction of the upper airways. As a general rule, the patient must have normal intellectual functions in order to adapt to the wearing of the devices. The mobilizable, partial or total hinges must be marked with the name of each bearer or other means of identification. Patients with a confused mental state can wander their prostheses and, unintentionally, „evade“ the prostheses of another person under hospital or institutionalization conditions.

The contraindication of total edentulous treatment by prostheses in psychiatric patients is due to serious illnesses, paranoid delirium, moderate-severe dementia, and patients unable to adapt to prostheses.

\section{Geriatric psychological implications of oral diseases}

Many elderly patients suffer from dental pain believing or being forced to live with them as they experience joint pains. Edentation is considered a natural, even physiological process of the advanced age, it is prevalent among older people all over the world and is highly associated with socio-economic status ${ }^{16}$. Total edentation occurs quite frequently in the elderly. The whole personality is marked by the change of attitude towards the new psychophysiological situation determined by the total edentation, a situation that the subject feels critical and frustrating.

Psychiatric disorders can be triggered by a total edentation on a modified psycho-biological land of senescence by aggregating biological and psychological negative factors. It can present:

- Accentuating personality traits. If personality has always been introverted, reserved, withdrawn, and inclined to meditation, these features will be emphasized.

- Neuroses. Situations of psychological tension caused by the decrease of its vital forces, the restriction of biological possibilities, the social entourage that observes the infirmity or the weakness of the elderly 
until soon active and authoritarian will make the transition sometimes imperceptible from normal to pathological. Thus, there will be defence attitudes, accentuated conservatism, rigidity, anxiety and prudence, hypochondria, psychic asthenia.

- Psychosis. The emergence of psychosis is undoubtedly linked to the emergence of a new disease, in our case, of total edentation. The patient will describe a series of symptoms related to taste changes, pain in the tongue or jaw, and the obsession with an intraoral neoplasm.

Psychic changes occur primarily due to the absence of arcade teeth that brutally installs the state of infirmity, „visible“. The psychosomatic appearance of the face implies a state of frustration of total edentation for sentimental or everyday life, negative emotions are amplified and ultimately translated into states generating neuroses or psychoses.

The limitation or absence of smile at total edentation due to the appearance of the dysphysiognomonic appearance, the repeated restraints in expressing the feelings of joy, affection, communication, change the social status of the patient in the family, professional or social relations. The state of total edification involves a disability that can often occur brutally through dental extractions, infirmity that cannot be hidden or removed immediately. It is objectively and subjectively sensed by the patient and seen by the entourage around him as ,totally aged with a Voltaire-like aspect". The lack of professional or social utility or even social withdrawal occurs for the sick.

The mental picture can be increased in relation to the age, with decreased physical capacity, with the appearance or worsening of certain general illnesses, resulting in depression and a state of inner conflict or with others. In a study, on identified that there is an important relationship between tooth loss and psychological factors: depression, anxiety and stress levels ${ }^{17}$.

Aesthetic disturbances are particularly relevant, producing a shocking effect by installing the image of aging differently interpreted by the patient depending on personality, cultural level, educational level, gender, age. Our emotions and actions are inseparable from the aesthetics of our body. We can talk about a true loss of physical identity, changes in dynamic images from oral expressions.

The affective or sensual physiological activity is signaled in the bucco-labial sphere, the sensitivity characteristic sensually influences the dynamic human relationships. The aesthetic and emotional aspect can be achieved by the spatial relations between the two upper and lower lips, the visibility of the alveolar edge and the teeth. Obtaining the aesthetic image of static and dynamic relationships of the lips, creating sensations or feelings that give human beings agreeable or appealing sensations and feelings can achieve the individual's inner or outer psychic balance if the aesthetic goals have been achieved.

Restoring lost identity, improving infirmity, narcissistic aspiration, and regaining one's own smile is part of the aesthetic objectives that will underpin the curative treatment.

\section{Conclusions}

Dental conditions can affect the quality of elderly life. The rehabilitation treatment of these patients is the first step in changing their lifestyle. An informed dentist can improve both oral health and lifestyle through a careful analysis of biopsychosocial and dental needs.

It is necessary to educate the patient regardless of age as a first step for raising awareness of the oral cavity. This attitude actively involves the patient and promotes his involvement in his / her own health. In addition, it stimulates the positive self-image of the patient, increases his autonomy towards others, and also accepts social acceptance. It may be useful to organize regular courses for training caregivers of elderly people with disabilities.

Oral health is not separate from the general health, but maintaining oral health is definitely difficult and different in the old age. Even though, few elderly people have physical and/or mental situation that call for particular interest in the dental workplace, one should not presume that all elderly community shares these circumstances. In order to achieve health, it is necessary to know few aspects of old age.

Periodic dental check-up is important for the elderly patients because they are at increased risk for developing oral disorders because of changes in the aging process.

Preventive dentistry counseling for the geriatric patient is important, this includes two components: education and motivation. Discussion with the patient should be appropriate to the level of understanding of the individual elderly person.

The biopsychosocial concept is fundamental to find an optimal treatment for oral diseases. The oral health influences the mental health of patients, changing their self-esteem, mood and satisfaction, even influencing their social life and quality of life. This is an important factor that has a direct influence on the general health and quality of life of the older people, fundamental factors for „healthy aging“.

\section{Compliance with Ethics Requirements:}

„The authors declare no conflict of interest regarding this article“ 


\section{References}

1. Bhardwaj VK. Gerodentology - orodental care for elderly. Eur J Gen Dent 2012;1(1):15-19.

2. Bodnar DC, et al. Managementul dentar al pacientului cu probleme medicale complexe, Ed. Ars Docendi, Universitatea din București 2012, p. 27-51, 133-144, 156-158.

3. Little JW, Miller C, Rhodus N. Dental management of the medically compromised patient. Seventh edition, Mosby Elsevier, 2008, p. 2-17.

4. Drăghici R. The clinical geropsychology - the role of the psychologist in geriatrics. In Ciobanu A, Popa C. (Ed.), Psychiatry and Psychopathology - Practical Application. LAP Lambert Academic Publishing, Saarbrucken-Germany, 2015, p. 36-47.

5. Mitchell L, Mitchell DA. With contributions Nattress B. Oxford handbook of clinical dentistry, Third Edition, Oxford University Press, 2003, p. 3-25.

6. Davis DR. Patient evaluation and problems - oriented treatment planning. In: Summit J. B., Robbbins JW, Schwartz RS. Fundamentals of operative dentistry, Second Edition, Quintessence Publishing Co.Inc. 2001, p. 26-55

7. Anghel M. Diagnosticul oral. Ed. Orizonturi Universitare, Timișoara, 2004, p. 11-57, 159-203

8. Razak PA, Jose Richard KM, Thankachan RP, et al. Geriatric oral health: a review. J Int Oral Health. 2014; 6(6):110-116.

9. Hainsworth J, Buchanan H. Clinical psychology in dentistry - a guide to commissioners of clinical psychology services.
Briefing Paper no. 11. The Division of Clinical Psychology, The British Psychological Society 2009.

10. American Psychiatric Association. The Diagnostic and Statistical Manual of Mental Disorders, Fifth Edition (DSM-5), Arlington, VA, American Psychiatric Association, 2013.

11. Facco E, Zanette G. The odyssey of dental anxiety: from prehistory to the present. A narrative review. Front Psychol. 2017; 8:1155.

12. Bodnar T, Bodnar DC, Cristache CM, et al. Managementul dentar al pacientului cu afecțiuni psihice. Medicina Modernă 2010;XVII(10):538-543.

13. Plozza BL, Diamandescu IB. Dimensiunea psihosocială a practicii medicale. Ed. InfoMedica București, 2002, p. 19-27, 131-177.

14. Braunwald E, et al. Manual de medicină, ed. a 15-a, Ed. Științelor Medicale, Imprimeria „Ardealul“ Cluj, 2004, p. 168-177.

15. Balaceanu A, Olteanu D, Diaconu A, Aron G, Dina I, Diaconu C. Hypertension in a young male patient: chronic stress as the only trigger. Arch Balk Med Union 2017;52(2): 219-224.

16. Petersen PE. Continuous improvement of oral health in the $21^{\text {st }}$ century - the approach of the WHO Global Oral Health Programme. Community Dent Oral Epidemiol 2003;31:3-24.

17. Roohafza H, Afghari P, Keshteli AH, et al. The relationship between tooth loss and psychological factors. Community Dent Health 2015;32(1):16-9. 